\title{
SIKAP PETANI PALA PADA KEGIATAN PEMELIHARAAN TANAMAN PALA DI DESA KAUDITAN II KECAMATAN KAUDITAN KABUPATEN MINAHASA UTARA
}

\author{
Nurlina Umawaitina \\ Theodora Maulina Katiandagho \\ Lyndon Reindhardt Jacob Pangemanan
}

\begin{tabular}{ll}
\hline Naskah diterima melalui Website Jurnal Ilmiah agrisosioekonomi@ unsrat.ac.id & $:$ Jumat, 12 Juli2019 \\
Disetujui diterbitkan & $:$ Kamis, 25 Juli 2019 \\
\hline
\end{tabular}

\begin{abstract}
This study aims to examine how attitudes of nutmeg farmers in maintenance activities consist of weeding activities, fertilizing activities and activities for controlling weeds and pests and diseases; and identifying factors that influence the attitude of nutmeg farmers to maintenance activities. This research was conducted in Kauditan II Village, Kauditan Subdistrict, North Minahasa Regency, from November to December 2017. The sampling method was done purposively by limited only to nutmeg farmers, namely as many as 20 nutmeg farmers. The data used are primary data and secondary data. Primary data is data obtained from direct interviews with nutmeg farmers. Secondary data was obtained from the Kauditan II Village Office and the internet through google searching to obtain articles from various journal articles relating to the topic of research on the attitude of nutmeg farmers to nutmeg plant maintenance activities. The data obtained were analyzed using descriptive analysis and presented in table form. The results showed that (1) the cognitive and affective attitude of nutmeg farmers to weeding, fertilizing and controlling weed/weed plants and disease pests showed an attitude of knowing and liking with a percentage of $100 \%$. However, the conative attitudes of nutmeg farmers to weeding, fertilizing and controlling weed/weed crops and disease pests showed that $78.33 \%$ means that farmers did three (3) activities of maintenance activities and as many as $21.67 \%$ of farmers did not implemented. ${ }^{*}$ eprm*
\end{abstract}

Keywords: attitude, nutmeg farmers, nutmeg plant maintenance activities, Kauditan II Village, North Minahasa

\begin{abstract}
ABSTRAK
Penelitian ini bertujuan untuk mengkaji bagaimana sikap petani pala pada kegiatan pemeliharaan yang terdiri atas kegiatan penyiangan, kegiatan pemupukan dan kegiatan pengendalian tanaman pengganggu/gulma serta hama dan penyakit; dan mengidentifikasi faktor-faktor yang mempengaruhi sikap petani pala terhadap kegiatan pemeliharaan. Penelitian ini dilaksanakan di Desa Kauditan II Kecamatan Kauditan Kabupaten Minahasa Utara pada bulan November sampai bulan Desember 2017. Metode Pengambilan sampel dilakukan secara sengaja (purposive sampling) dengan dibatasi hanya pada petani pala, yaitu sebanyak 20 petani pala. Data yang digunakan adalah data primer dan data sekunder. Data primer merupakan data yang diperoleh dari wawancara langsung pada petani pala. Data sekunder diperoleh dari Kantor Desa Kauditan II dan internet melalui google searching untuk mendapatkan artikel dari berbagai artikel jurnal yang berkaitan dengan topik penelitian tentang sikap petani pala pada kegiatan pemeliharaan tanaman pala. Data yang diperoleh dianalisis menggunakan analisis deskriptif dan disajikan dalam bentuk tabel. Hasil penelitian menunjukkan bahwa (1) Sikap kognitif dan afektif petani pala terhadap kegiatan penyiangan, pemupukan dan pengendalian tanaman penggangu/gulma dan hama penyakit menunjukkan sikap tahu dan suka dengan presentase $100 \%$. Namun pada sikap konatif petani pala terhadap kegiatan penyiangan, pemupukan dan pengendalian tanaman penggangu/gulma dan hama penyakit menunjukkan bahwa 78,33\% artinya petani melakukan tiga (3) kegiatan pemeliharaan tersebut dan sebanyak $21,67 \%$ petani tidak melakukan kegiatan tersebut. ${ }^{*}$ eprm* $^{*}$
\end{abstract}

Kata kunci : sikap, petani pala, kegiatan pemeliharaan tanaman pala, Desa Kauditan II, Minahasa Utara.

Agrisosioekonomi:

Jurnal Transdisiplin Pertanian (Budidaya Tanaman, Perkebunan, Kehutanan, Peternakan, Perikanan), Sosial dan Ekonomi 347 


\section{PENDAHULUAN}

\section{Latar Belakang}

Tanaman pala (Myristica fragrans Houtt) merupakan tanaman asli Indonesia yang sangat potensial sebagai komoditas perdagangan didalam dan luar negeri (Ekspor). Sudah sejak lama tanaman pala dikenal sebagai bahan rempah-rempah dan mempunyai kedudukan penting sebagai sumber minyak atsiri yang sangat dibutuhkan dalam berbagai industri, antara lain Obat-obatan, parfum, dan kosmetik. Sehingga Indonesia merupakan produsen pala terbesar di dunia $(70-75 \%)$. Komoditas pala Indonesia sebagian besar dihasilkan oleh perkebunan rakyat yaitu sekitar 98,84\% (Balai Komoditi Industri, Departemen 2009 dalam Palijama dkk, 2012).

Pala merupakan komoditas perkebunan yang bernilai ekonomi tinggi dan hampir keseluruhan bagian tanaman dapat dimanfaatkan, seperti biji, bunga, fuli dan bagian daging buah dapat digunakan untuk industri makanan, minuman, pengawetan ikan, pembuatan sabun dan obat herbal. Kegiatan pemeliharaan merupakan upaya yang diperlukan untuk mencapai hasil maksimal dari tanaman pala yang di usahakan.

Dengan demikian pemeliharaan tanaman merupakan salah satu factor yang perlu diperhatikan. Kegiatan pemeliharaan tanaman pala yang dilakukan secara kontinu, teliti dan cermat, meliputi: penyiangan, pemupukan dan pengendalian tanaman pengganggu/gulma hama dan penyakit.

Kecepatan menerima terhadap teknologi tidaklah sama tergantung kepada sikap dan kondisi masing-masing petani seperti tingkat pendidikan, tingkat kosmopolitan, tingkat umur dan lamanya bertani (Suhardiyanto, 1991 dalam Hasyim, 2006).

Tingkat produktifitas tanaman pala di Kecamatan Kauditan jauh berada dibawah tingkat pala produktifitas nasional. Data BPS Minahasa Utara (2017), menjelaskan tentang luas panen tanaman pala di Kecamatan Kauditan adalah seluas 522 ha dengan jumlah produksi yang dihasilkan 158 ton sehingga produktivitas yang diperoleh yaitu 0,30 ton/ha yang berada dibawah tingkat produktifitas tanaman pala nasional. Berdasarkan keterangan di atas, maka peneliti berpendapat bahwa petani pala di Kecamatan Kauditan pala, di Desa karena kurangnya memberikan perhatian terhadap tanaman pala.

Hal ini ditunjukkan dengan kurangnya hasil produksi serta produktivitas yang diperoleh petani pala. Untuk itu Peneliti juga tertarik untuk mengetahui faktor yang mempengaruhi sikap atau perilaku petani terhadap proses pemeliharaan tanaman pala yang terdapat di Desa Kauditan II Kecamatan Kauditan.

\section{Rumusan Masalah}

Berdasiarkan latar belakang, maka yang menjadi faktor rendahnya produksi pala dalam rumusan masalah peneltian ini ialah :

1. Bagaimanakah sikap petani pala dalam kegiatan pemeliharaan tanaman pala di Desa Kauditan II.

2. Komponen-komponen apa saja yang mempengaruhi sikap petani pala pada kegiatan pemeliharaan.

\section{Tujuan Penelitian}

1. Mengkaji sikap petani pala pada kegiatan pemeliharaan Penyiangan, pemupukan dan pengendalian tanaman pengganggu/ gulma hama dan penyakit.

2. Mengidentifikasi komponen-komponen yang mempengaruhi sikap petani pala pada kegiatan pemeliharaan penyiangan, pemupukan dan pengendalian tanaman pengganggu/gulma hama dan penyakit.

\section{Manfaat Penelitian}

Manfaat penelitian yang diharapkan ialah menambah pengetahuan mengenai sikap petani pala pada kegiatan pemeliharaan.

\section{METODE PENELITIAN}

\section{Waktu dan TempatPenelitian}

Penelitian ini dilaksanakan selama 2 bulan, yaitu dari bulan November sampai Desember 2017. Tempat penelitiandi Desa Kauditan II, Kabupaten Minahasa Utara. 


\section{Metode Pengumpulan Data}

Data yang digunakan dalam penelitian ini adalah data primer dan data sekunder. Data primer merupakan data yang diperoleh dari wawancara langsung pada petani pala.

Data sekunder adalah data-data yang dikumpulkan dari instansi atau lembaga yang berkaitan dengan penelitian, dengan cara mencatat langsung data yang bersumber dari dokumentasi yang ada. Data sekunder yang dikumpulkan dalam penelitian ini berupa data monografi dan data-data yang berkaitan dengan petani pala.

\section{Metode Pengambilan Sampel}

Objek dalam penelitian ini adalah masyarakat Desa Kauditan II yang merupakan petani pala. Pengambilan sampel dalam penelitian ini dilakukan secara sengaja (purposive sampling), yaitu sebanyak 20 petani pala.

\section{Karakteristik Responden}

1. Umur masyarakat adalah usia masyarakat yang menjadi responden dalam penelitian ini.

2. Pendidikan adalah jenjang pendidikan akhir masyarakat yang menjadi responden dalam penelitian dan di nyatakan dalam tingkat SD, SLTP, SMA, Perguruan tinggi.

3. Jumlah anggota keluarga adalah jumlah tanggungan masyarakat sebagai responden dalam penelitian ini.

4. Pengalaman waktu kerja adalah pengalaman/pekerjaan yang pernah di tekuni oleh masyarakat sebagai responden dalam penelitian ini.

\section{Konsep Pengukuran Variabel}

Variabel yang diamati dalam penelitian ini adalah sikap. Sikap petani yang dinilai adalah bagaimana responden petani terhadap pemeliharaan pala. Tahapan pemeliharaan terdiri dari 3 yaitu :

1. Penyiangan

2. Pemupukan

3. Pengendaliaan tanaman penggangu/gulma hama dan penyakit.

\section{Analisis Data}

Data yang diperoleh dalam penelitian ini dianalisis dengan menggunakan analisis deskriptif dan disajikan dalam bentuk tabel.

\section{HASIL DAN PEMBAHASAN}

\section{Gambaran Umum Wilayah Penelitian}

Wilayah penelitian ini di laksanakan di Desa Kauditan II Kecamatan Kauditan Kabupaten Minahasa Utara. Desa Kauditan II terletak di ibu kota Kecamatan Kauditan. Desa Kauditan II merupakan wilayah datar dengan kemiringan antara $0 \mathrm{~s} / \mathrm{d} 25^{\circ}$ dari permukaan laut. Batas-batas Desa sebagai berikut:

- Sebelah Utara : Wilayah kepolisian Desa Kauditan I Kecamatan Kauditan dan Hutan Lindung Gunung Klabat.

- Sebelah selatan : Wilayah kepolisian Desa Kauditan I Kecamatan Kauditan dan Desa Tontalete Kecamatan Kema.

- Sebelah Barat : Wilayah kepolisian Desa Kauditan I Kecamatan Kauditan.

- Sebelah Timur : Wilayah Kepolisian Desa Tontalete Kecamatam Kema.

Desa Desa Kauditan II memiliki luas wilayah yaitu $\pm 1007 \mathrm{Ha}$ yang penggunaannya yaitu sebagai berikut:

\begin{tabular}{lccc} 
Tabel & $\begin{array}{c}\text { 1. } \\
\text { Presentase Luas } \\
\text { Penggunaan Lahan }\end{array}$ & Lahan, Dan & Masing-Masing \\
\hline \multirow{2}{*}{ No } & Penggunaan Lahan & $\begin{array}{c}\text { Luas Lahan } \\
(\mathrm{Ha})\end{array}$ & $\begin{array}{c}\text { Presentase } \\
(\%)\end{array}$ \\
\hline 1 & Pemukiman & 45 & 4 \\
2 & Tanah Persawahan & 33 & 3 \\
3 & Tanah Ladang & 165 & 16 \\
4 & Tanah Perkebunan Rakyat & 764 & 77 \\
\hline Total & & 1007 & 100 \\
\hline
\end{tabular}

Dari 1007 ha lokasi yang di miliki oleh Desa Kauditan II menurut penggunaan yang paling besar adalah tanah perkebunan rakyat, selanjutnya penggunaan kedua yang paling besar adalah tanah ladang. Selain itu sisanya yang lain digunakan untuk pemukiman dan persawahan.

\section{Keadaan Penduduk}

Total jumlah keseluruhan jumlah penduduk yang ada di Desa Kauditan II sebanyak 2. 521 jiwa, dengan rincian lakilaki berjumlah 1. 261 dan perempuan 1.260 jiwa. Dengan jumlah kepala keluarga 721 (KK). Sebagian besar masyarakat yang ada di 
Desa Kauditan II bermata pencarian petani pala, dan jumlah masyarakat yang bermata pencarian petani pala sebanyak 219 orang, dan selanjutnya yang bermata pencarian sebagai buruh sebanyak 113 orang, dan yang bermata percarian sebagai wiraswasta sebanyak 163 orang. Dan selanjutnya sebagian masyarakat yang ada di Desa Kaudita II belum bias di katergorikan sebagai petani pala, buruh maupun wiraswasta karena mereka belum memiliki pekerjaan yang tetap.

\section{Saranadan Prasarana}

Secara umum pembangunan dan perkembangan suatu wilayah ditentukan oleh sumber daya manusia serta di fasilitasi dengan sarana dan prasarana yang memadai dari wilayah tersebut. Sarana dan prasarana merupakan dua hal yang tidak dapat dipisahkan karena keduanya saling mengisi atau melengkapi. Sarana dan prasarana yang ada di Desa Kauditan II sebagai berikut:

\section{Pendidikan}

Pendidikan merupakan hal yang sangat pendidikan didalam kehidupan manusia dan pendidikan itu sendiri akan diperoleh setiap orang secara formal maupun non formal.

Prasarana pendidikan yang terdapat di Desa Kauditan dapat dilihat pada Tabel 2.

Tabel 2. Jumlah Gedung Sekolah di Desa Kauditan II

\begin{tabular}{llc}
\hline No. & \multicolumn{1}{c}{ Gedung Sekolah } & Jumlah Gedung \\
\hline 1 & Taman Kanak-Kanak (TK) & 1 buah \\
& $\begin{array}{l}\text { Imanuel } \\
2\end{array}$ & Taman Kanak-Kanak (TK) Nurul \\
& Huda & 1 buah \\
3 & SDN Inpres Kauditan II & 1 buah \\
4 & SD Cokroaminoto Kauditan II & 1 buah \\
\hline & Jumlah & 4 buah \\
\hline
\end{tabular}

\section{Agama}

Setiap orang berhak memilih dan memeluk agama yang merupakan kepercayaan dari setiap orang atau setiap agama nya masing-masing. Tempat ibadah yang merupakan prasarana yang ada di Desa Kauditan II dapat dilihat pada Tabel 3.

\begin{tabular}{|c|c|c|}
\hline Tabel & 3. Jumlah Tempat Ibadah di Desa & Ka \\
\hline No. & Tempat Ibadah & Jumlah Gedung \\
\hline 1 & Mesjid Nurul Huda Kauditan II & 1 buah \\
\hline 2 & Taman Pengajian Kauditan II & 1 buah \\
\hline 3 & Gereja GMIM Paulus Kauditan & 1 buah \\
\hline 4 & Gereja Pantekosta (GPDI) Kauditan & 1 buah \\
\hline 5 & Gereja Advent Kauditan & 1 buah \\
\hline 6 & Gereja Katolik Kauditan & 1 buah \\
\hline \multirow[t]{2}{*}{7} & Kegerakan Roh Kudus Kauditan & 1 buah \\
\hline & Jumlah & 7 buah \\
\hline
\end{tabular}

\section{Karakteristik Responden}

\section{Umur}

Kemampuan atau melakukan aktifitas secara fisik bahkan cara berfikir seseorang sangat di pengaruhi oleh faktor umur. Demikian juga dengan para petani dalam melakukan pekerjaannya, petani yang memiliki umur yang lebih mudah tentunya mempunyai kondisi fisik yang lebih kuat serta mempunyai daya piker yang lebih kreatif. Di bandingkan dengan yang berumur tua. Karateristik responden berdasarkan tingkat umur dilihat pada Tabel 4 .

Tabel 4. Jumlah Responden Berdasarkan Umur

\begin{tabular}{lcc}
\hline Umur & Jumlah Responden (Orang) & Presentase (\%) \\
\hline$<39$ & 9 & 45 \\
$40-59$ & 8 & 40 \\
$>60$ & 3 & 15 \\
\hline Jumlah & 20 & 100
\end{tabular}

Sumber : Data Primer 2018

Tabel 4 menunjukkan bahwa umur responden termuda 23-39 tahun dan umur responden tertua 40-59 tahun. Rata-rata umur responden 60-68. kebanyakan responden berada dibawah 59 tahun (85\%).

\section{Tingkat Pendidikan}

Tabel 5 menunjukkan bahwa tingkat pendidikan responden dimana 9 atau 5 persen responden mempunyai pendidikan hanya sampai pada tingkat SD, sedangkan responden yang mempunyai tingkat pendidikan batas SMP hanya 1 responden atau (5\%) dari jumlah responden yang di teliti. Selanjutnya ada (10\%) atau $(50 \%)$ responden yang mempunyai tingkat pendidikan hanya sebatas SMA. Dengan demikian maka dapat di simpulkan bahwa pendidikan dari pada responden cukup baik, tapi harus ada pelatihan-pelatihan informal dari Dinas Pertanian untuk menambah wawasan dari pada para responden tersebut. 


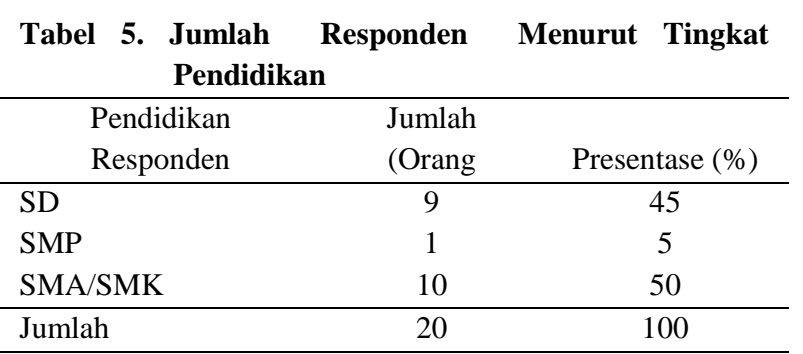

Sumber: Data Primer 2018

\section{Jumlah Tanggungan Dalam Keluarga}

Keluarga terdiri dari bapak, ibu dan anak. semakin bertambah jumlah anggota keluarga maka tingkat komsumsi pun ikut bertambah.

\begin{tabular}{|c|c|c|c|c|c|}
\hline \multicolumn{4}{|c|}{$\begin{array}{l}\text { Jumlah T } \\
\text { Responden }\end{array}$} & Dalam & \multirow{2}{*}{$\begin{array}{l}\text { n Keluarga } \\
\text { Presentase }\end{array}$} \\
\hline \multicolumn{3}{|c|}{ Jumlah Tanggungan } & Responden & & \\
\hline \multicolumn{3}{|c|}{5} & 11 & & 42 \\
\hline \multicolumn{3}{|c|}{4} & 6 & & 33 \\
\hline \multicolumn{3}{|c|}{3} & 3 & & 25 \\
\hline \multicolumn{3}{|c|}{ Jumlah } & 20 & & 100 \\
\hline
\end{tabular}

Sumber : Data Primer 2018

Tabel 6 menunjukkan bahwa jumlah anggota keluarga sebanyak 5 tanggungan keluarga yaitu ada 11 responden atau (42\%), sedangkan jumlah tanggungan keluarga terbanyak kedua ada 4 responden dan ada 6 kepala keluarga $(\mathrm{KK})$ dan untuk tanggunggan keluarga yang paling sedikit yaitu sebanyak tiga 3 responden, dengan jumlah kepala keluarga sebanyak 3 atau (25\%.). Dengan demikian maka dapat di simpulkan bahwa jumlah anggota keluarga responden di Desa Kauditan II Kecamatan Kauditan Kabupaten Minahasa Utarasebanyak 5 responden dengan jumlah kepala keluarga 11 responden.

\section{Status Kepemilikan}

Berdasarkan hasil wawancara bahwa dengan responden, bahwa status lahan yang di tanami pala adalah lahan milik responden (petani) sendiri.

\section{Komponen-Komponen Tentang Sikap Petani Pala}

A. Komponen yang mempengaruhi sikap petani tentang kegiatan penyiangan.

1) Dana

2) Motivasi untuk meningkatkan produksi

3) Kebersihan lahan
B. Komponen yang mempengaruhi sikap petani tentang kegiatan pemupukan.

1) Motivasi untuk meningkatkan produksi

2) Dana

C. Komponen yang mempengaruhi sikap petani tentang pengendalian tanaman pengganggu/ gulma hama dan penyakit.

1) Dana

\section{Pembahasan}

\section{Penyiangan}

Penyiangan adalah hal sangat penting pada semua tanaman terlebih khusus pada tanaman pala. Karena dengan melakukan penyiangan yang rutin maka tanaman pala yang di budidayakan tidak akan kekurangan unsur hara dan tanaman pala tersebut akan menghasilkan buah yang baik.

Tabel 7. Sikap Petani Pala Pada Kegiatan Penyiangan Tahun 2018

\begin{tabular}{ccc}
\multicolumn{2}{c}{ Tahun } & \\
\hline Sikap Petani & $\begin{array}{c}\text { Jumlah Petani } \\
\text { (Orang) }\end{array}$ & Presentase (\%) \\
\hline Tahu & 20 & 100 \\
\hline Jumlah & 20 & 100 \\
\hline
\end{tabular}

Sumber : Data Primer 2018

Tabel 7 menunjukkan bahwa rata-rata petani pala yang ada di Desa Kauditan II sudah mengetahui cara melakukan penyiangan pada tanaman pala. Maka tanaman pala yang ada di Desa Kauditan II akan menghasilkan buah yang baik, dan akan untuk meningkatkan pendapatan ekonomi dan memenuhi kebutuhan sehari-hari.

\section{Pemupukan}

Pemupukan merupakan salah satu proses penting dalam budidaya tanaman pala. Karena proses pemupukan akan sangat menetukan keberhasilan produksi tanaman pala tersebut. Selain itu, petani harus tahu jenisjenis pupuk apa yang akan diberikan kepada tanaman pala.

Tabel 8. Sikap Petani Pala Pada Kegiatan Pemupukan Tahun 2018

\begin{tabular}{ccc}
\hline Sikap Petani & Jumlah Petani (Orang) & Presentase (\%) \\
\hline Tahu & 20 & 100 \\
\hline Jumlah & 20 & 100 \\
\hline Sumber : Dat Primer 2018 &
\end{tabular}

Sumber : Data Primer 2018 
Tabel 8 menunjukkan bahwa seluruh responden petani pala yang ada di Desa Kauditan II tahu cara melakukan pemupukan tanaman pala. Dari 20 responden yang di ambil untuk di jadikan sampel penelitian rata-rata petani tahu cara memberikan pupuk pada setiap tanaman yang sesuai dengan kebutuhannya. Caranya tentu sudah jelas, yakni mengisih tanah dengan unsur hara yang dibutuhkan oleh tanaman supaya tanaman yang di budidayakan tumbuh subur dan memberikan hasil yang memuaskan. Karena petani pala yang ada di Desa Kauditan II bukan orang yang baru membudidayakan tanaman pala. Dan semua petani pala yang ada di Desa Kauditan II mereka sudah mengetahui cara melakukan pemupukan.

Menurut Sutedjo (2002), bahwa pemupukan adalah pemberian atau penambahan bahan-bahan/zat-zat pada tanaman atau tanah untuk mencukupi keadaan makanan/unsur hara dalam tanah yang tidak cukup di dalamnya. Dengan kata lain bahwa pupuk juga menentukan hasil produksi dari tanaman pala tersebut. Karena dengan memberikan pupuk yang baik terhadap tanaman pala, maka unsur hara yang di butuhkan oleh tanaman akan tercukupi. Pemupukan yang tidak tepat dapat menimbulkan kerusakan seperti pupuk terbuang percuma, tidak mencapai sasaran sehingga tidak efisien dalam kadarnya berkurang kualitasnya.

\section{Pengendalian Tanaman Pengganggu/ Gulma dan Hama Penyakit}

Pengendalian merupakan suatu proses untuk menurunkan populasi hama hingga pada tingkat yang tidak merugikan petani. Bisa menggunakan pestisida, agen hayati, dan cara-cara penurunan populasi lainnya. Jadi pengendalian semata-mata bermaksud untuk membunuh hama sampai habis tetapi mengatur populasi hama sedemikian rupa, sehingga tercipta suatu keadaan yang seimbang dalam ekosistem pertanian tanpa mengakibatkan kerugian ekonomis karena turunnya produksi tanaman.

Tabel 9. Sikap Petani Pala Terhadap Kegiatan Pengendalian Hama Dan Penyakit Tahun 2018

\begin{tabular}{lcc}
\hline Sikap Petani & $\begin{array}{c}\text { Jumlah Petani } \\
\text { (Orang) }\end{array}$ & Presentase (\%) \\
\hline Tahu & 15 & 75 \\
Suka & 5 & 25 \\
Tidak & & 0 \\
Lakukan & 0 & 100 \\
\hline Jumlah & 20 &
\end{tabular}

Sumber : Data Primer 2018

Tabel 9 menunjukkan bahwa 15 responden atau $75 \%$ petani di Desa Kauditan II mengetahui cara mengendalikan hama penyakit atau gulma pada tanaman pala. Dan untuk selanjutnya ada 5 responden atau (25\%) petani yang suka dalam mengendalikan tanaman pengganggu/gulma dan hama penyakit. Sedangkan petani yang tidak mengetahui cara mengendalikan tanaman penggangu atau gulma dan hama penyakit, dengan kata lain mereka tidak tahu cara mengendalikan tanaman pengganggu/gulma hama dan penyakit.

Dengan demikian, maka tanaman pala yang di usahakan oleh petani yang ada di Desa Kauditan II mampu menjaga tanaman pala dari serangan tanaman pengganggu/gulma hama dan penyakit. Sedangkan petani yang tidak mengetahui cara mengendalikan tanaman penggangu atau gulma dan hama penyakit, dengan kata lain mereka tidak tahu cara mengendalikan tanaman pengganggu/gulma hama dan penyakit. Dengan demikian, maka tanaman pala yang di usahakan oleh petani yang ada di Desa Kauditan II mampu menjaga tanaman pala dari serangan tanaman pengganggu/gulma hama dan penyakit. Sikap responden terhadap pengendalian tanaman pengganggu/gulma dan hama penyakit pada tanaman pala dapat dilihat pada Tabel 10, Tabel 11, dan Tabel 12. 


\begin{tabular}{|c|c|}
\hline $\begin{array}{ll}\text { Tabel 10. } & \begin{array}{l}\text { Sikap Responden } \\
\text { Penyiangan } 2018\end{array}\end{array}$ & Terhadap Kegiatan \\
\hline Sikap Responden & Jumlah Responden \\
\hline \multicolumn{2}{|l|}{ Kognitif } \\
\hline Tahu & 20 \\
\hline Tidak Tahu & 0 \\
\hline \multicolumn{2}{|l|}{ Afektif } \\
\hline Suka & 20 \\
\hline Tidak Suka & 0 \\
\hline \multicolumn{2}{|l|}{ Konatif } \\
\hline Melakukan & 15 \\
\hline Tidak Melakukan & 5 \\
\hline
\end{tabular}

Tabel 11. Sikap Responden Terhadap Kegiatan Pemupukan 2018

\begin{tabular}{lc}
\hline \multicolumn{1}{c}{ Sikap Responden } & Jumlah Responden \\
\hline Kognitif & \\
\hline Tahu & 20 \\
Tidak Tahu & 0 \\
\hline Afektif & \\
\hline Suka & 20 \\
Tidak Suka & 0 \\
\hline Konatif & \\
\hline Melakukan & 16 \\
Tidak Melakukan & 4 \\
\hline
\end{tabular}

Sumber : Data Primer 2018

Tabel 12. Sikap Responden Terhadap Kegiatan Pengendalian Tanaman Penganggu /Gulma Hama dan Penyakit 2018

\begin{tabular}{lc}
\hline \multicolumn{1}{c}{ Sikap Responden } & Jumlah Responden \\
\hline Kognitif & \\
\hline Tahu & 20 \\
Tidak Tahu & 0 \\
\hline Afektif & \\
\hline Suka & 20 \\
Tidak Suka & 0 \\
\hline Konatif & \\
\hline Melakukan & 16 \\
Tidak Melakukan & 4 \\
\hline
\end{tabular}

Sumber : Data Primer 2018

\section{KESIMPULAN DAN SARAN}

\section{Kesimpulan}

Berdasarkan hasil penelitian maka yang menjadi kesimpulan dalam penelitian ini yaitu:

1. Sikap kognitif dan afektif petani pala terhadap tahap penyiangan, pemupukan dan pengendalian tanaman penggangu/gulma dan hama penyakit menunjukkan sikap tahu dan suka dengan presentase $100 \%$. Namun pada sikap konatif petani pala terhadap tahapan penyiangan, pemupukan dan pengendalian tanaman penggangu/gulma dan hama penyakit menunjukkan bahwa $78,33 \%$ artinya petani melakukan 3 tahapan tersebut dan sebanyak $21,67 \%$ petani tidak melakukan tahapan tersebut.

2. Komponen yang berpengaruh terhadap tahap penyiangan, pemupukan dan pengendalian tanaman penggangu/gulma dan hama penyakit adalah dana, motivasi untuk meningkatkan produksi dan kebersihan lahan.

\section{Saran}

Berdasarkan kesimpulan maka saran dari peneliti sebagi berikut. Untuk meningkatkan hasil produksi tanaman pala, maka petani yang ada di Desa Kauditan II harus tahu cara membudidaya kan tanaman pala, dan harus menjaga atau melindungi tanaman pala dari serangan tanaman pengganggu / gulma hama dan penyakit.

\section{DAFTAR PUSTAKA}

BPS Kabupaten Minahasa Utara. 2017. Kecamatan Kauditan Dalam Angka. https:// minut kab. bps. go. id. Diakses tanggal 27 Oktober 2017.

Hasyim H. 2006. Analisis Hubungan Karakteristik Petani Kopi Terhadap Pendapatan (Study Kasusu : Desa Dolok Saribu Kecamatan Paguran Kabupaten Tapanuli Utara). Jurnal Komunikasi Penelitian Volume 18 (1) 2006. Repository. usu. ac. id. Diakses tanggal 30 Oktober 2017.

Sutedjo. M. M. 2002. Pupuk dan cara pemupukan. Rineka Cipta, Jakarta. 
Palijama W, J. Riry dan A.Y. Wattimena.

2012. Komunitas Gulma Pada

Pertanaman Pala (Myristica fragrans $\mathrm{H}$ )

Belum Menghasilkan Dan

Menghasilkan Di Desa Hutumuri Kota

Ambon. Jurnal Ilmu Budidaya Tanaman

Volume 1, Nomor 2, Oktober 2012.https:/ /ejournal .unpatti. ac. id.

Diakses tanggal 30 Oktober 2017. 